\title{
Isolation and Molecular Characterization of Circulating Foot and Mouth Disease Virus in Egypt During 2018-2020
}

\author{
Safaa Mahmoud Mohamed Ismael ${ }^{*}$, Sayed Ahmed Salem² and Mohammed Saed Elshahidy ${ }^{3}$ \\ ${ }^{1}$ Animal Health Institute Zagazig Branch, Zagazig, Egypt \\ ${ }^{2}$ Animal Health Institute, Doki, Egypt \\ ${ }^{3}$ Faculty of Veterinary Medicine, Suez Canal University, Ismailia, Egypt \\ *Corresponding author: sofiaend@ymail.com
}

Article History: 20-237 Received: 01-Dec-20 Revised: 23-Jan-21 Accepted: 16-Feb-21
ABSTRACT
Foot and Mouth Disease (FMD) is a contagious viral disease with high economic losses and primary animal health
concerns. FMDV type SAT2 is endemic in Egypt since 2012. This work aimed to characterize the circulating FMDV
SAT2 strains genetically in Egypt from 2018 to 2020. A total of 209 vesicular fluids and tongue epithelium were
collected from infected cattle and buffaloes in Sharkia, Ismailia, and Dakhlia provinces. All samples were examined by
real-time PCR and conventional PCR for FMDV using pan- serotype and serotype-specific primers targeting the VP1
region. Out of 209 samples, 45 infected animals were positive for FMDV SAT2 virus, 29 cattle (21.5\%), and 16
buffaloes (13.6\%). No FMDV serotype A or O were detected. The highest prevalence of FMDV SAT2 was observed in
Sharkia province with a percentage of 10\% followed by Ismailia and Dakhlia with a rate of 2.9 and 0.9\%, respectively.
Three FMDV SAT2 positive samples represented as Sharkia 2018 and Sharkia 2019 and Ismailia 2020 were selected
for sequencing and phylogenetic analysis of VP1. Sequencing and phylogenetic analysis of VP1of the three Egyptian
strains demonstrated that these strains are closely related to other Egyptian strains in gene bank as Alex 2018
(MK4933346), Ismailia 2018 (MK4933341), and Menofia 2018 (MT199283) with homology ranged from 95.8 to
98.2\%. Phylogenetic tree of FMDV SAT2 showed clustering of Sharkia 2018, Sharkia 2019, and Ismailia 2020 with
Libya 2012 topotype VII with three amino acid substitutions at the site 24, 28, and 52.

Key words: Foot and mouth disease, Egypt, Cytopathogenic effects, qRT-PCR, FMD Strains.

@202I IJVS - All Rights Reserved

\section{INTRODUCTION}

Foot and mouth disease (FMD) is an extremely transmissible viral disease transmitted from animals with open fork leg with great economic consequences worldwide (Kasambula et al. 2012). Economically, Foot and mouth disease virus affects both the production and reproduction of dairy and feedlot animals, producing reduction or loss of milk and meat production and deterioration in body conditions in addition to animal movement restriction, premature culling, with vaccination and treatment cost (Bachrach 1968). The disease is transmitted by airborne or by direct and indirect contact with infected animals (Alexanderson et al. 2000).

Foot and mouth disease (FMDv) is the etiological agent of FMD and belongs to the family Picornaviridae. At the genetic level FMDV has been classified into seven immunologically distinct serotypes (O, A, C, SAT1, SAT2, SAT3, and Asia1 (ICTV 2000). FMD virus has spherical shape non-enveloped, icosahedral symmetry and consists of a single-stranded, positive-sense RNA molecule of approximately 8,500 nucleotides. FMDV genome has 5 untranslated regions (UTR), containing untranslated nucleic acid regions, protein-coding region (ORF), which codes for both structural and non-structural proteins; and 3' UTR un-coding coding region (Jamal and Blesham 2013). Egypt has several outbreaks of FMDV since 1951 with FMD-SAT2 introduction (Diab et al. 2019).

FMDV serotype O, A, SAT2, and C have circulated in North Africa, historically. FMD serotype $\mathrm{O}$ is the most prevalent serotype, followed by serotype A. Serotype C and SAT2 have been reported in Tunisia and Egypt, respectively. Before 1999, the last reported outbreaks in North African countries were in: Algeria (1990, serotype O); Morocco (1992, serotype O); Libya (1994, serotype O); Tunisia (1994, serotype O); and Egypt (1997 serotype O), (WRLFMD 2017).

Cite This Article as: Ismael SMM, Salem SA and Elshahidy MS, 2021. Isolation and molecular characterization of circulating foot and mouth disease virus in Egypt during 2018-2020. International Journal of Veterinary Science 10(3): 162-171. https://doi.org/10.47278/journal.ijvs/2020.046 
During the OIE 2019 meeting, the experts reported the distribution of FMD virus lineages in different parts of the world with particular attention have focused on North Africa, where FMD outbreaks due to serotypes A (A/AFRICA/G-IV) and O (O/EA-3) were reported in 2017 and 2018. Network partners shared data about the frequent emergence of FMD viruses such as O/ME-SA/Ind-2001) and (A/AsiaG-VII) from south Asian countries and their onward spread in West Eurasian and southeast and East Asia (OIE 2019; Nermeen et al. 2019).

Several research publications reported three of the seven serotypes in different Egyptian provinces including serotype O, A, and SAT-2 (Ahmed et al. 2012). In these outbreaks, lots of topotypes and lineages were implicated. The incursions of new serotypes or topotypes are associated with the importation of animals from African countries that reported to be endemic in FMD and the use of unsuitable vaccines, making the animals exposed to infections with different atypical FMD variants (Nampana et al. 2013). Due to the high mutation rate of FMDV SAT2 and the possibility of evolution of new strains that breaches immunity, continuous observation with the genetic characterization of the spreading FMDV strains is critical for good appropriate vaccination and effective control measures. Thus, this work aimed to isolate and molecularly describe the circulating FMDV SAT2 strains throughout the epidemic that happened in Sharkia, Ismailia, and Dakhlia province during 2018-2020. Genetic analysis of FMDV SAT2 focusing on nucleotide and amino acid variations in VP1 to guarantee the efficacy of the vaccine in Egypt.

\section{MATERIALS AND METHODS}

\section{Sampling and Sample Preparation}

A total of 209 vesicular fluids and tongue epithelium were collected from cattle and buffaloes in Sharkia $(n=131)$, Ismailia $(n=49)$, and Dakhlia $(n=29)$ provinces and examined for direct detection and serotyping of FMDV in clinical samples. Firstly, the animals were calm down by techniques of holding for clinical symptoms examination and confirmation. Tongue epithelium from the tongue or buccal mucosa was collected from a ruptured or recently ruptured vesicle during the study period (2018-2020). Two grams of each sample were diluted in TE buffer up to 1:5 dilution. The mixture was ground and homogenized in a tissue lyser. Phosphate buffer $(10 \mathrm{ml})$ was added to the grinded tissues to centrifugation at $10000 \mathrm{rpm}$ for 10 minutes and the upper layer was blended with antibiotics to be used for virus isolation in BHK21 cells or RNA extraction according to the method described by Negussie et al. (2011) and Ding et al. (2013).

\section{Virus Isolation}

Forty-five PCR positive samples were confirmed by virus isolation in BHK21 cell culture. Tongue epithelium and vesicular fluids were grounded in sterile mortar and pestle up to $10 \%$ final concentration. The mixed solution was purified by centrifugation at $3000 \mathrm{rpm}$ about $10 \mathrm{~min}$ at $4^{\circ} \mathrm{C}$ the upper layer was inoculated in a confluent monolayer sheet and incubated at $37^{\circ} \mathrm{C}$ in $5 \% \quad \mathrm{CO} 2$ incubator described by Negussie et al. (2011) and Ding et al. (2013). The characteristic cytopathic feature was observed twice daily in the inoculated cells by an inverted microscope (TELAVAL3, Germany).

\section{Reverse Transcription, cDNA Preparation}

The RNA of infected cells was extracted by using the Trizol Easy-Red TM Total RNA extraction Kit (Intron Biotechnology, Korea) from the original sample according to the manufacturer's protocol. High-Capacity cDNA Reverse Transcription kit (Applied Biosystems, Part No. 4374966) was utilized for the synthesis of the first-strand cDNA. Reaction mixture consisting of 10X RT buffer, extracted RNA, 25XdNTP Mix (100mM), 10X RT random primers, MultiScribe TM Reverse Transcriptase, RNase inhibitor, and Nuclease-free water. This blended solution was put in the thermal cycler for $10 \mathrm{~min}$ at $25^{\circ} \mathrm{C}, 120 \mathrm{~min}$ at $37^{\circ} \mathrm{C}$, for $5 \mathrm{~min}$ at $85^{\circ} \mathrm{C}$, and cooled to $4^{\circ} \mathrm{C}$ according to the manufacture instructions.

\section{Real-Time PCR (RT-PCR)}

FMDV SAT2 isolates were identified by real-time PCR using the Quantitec probe RT-PCR kit (Qiagen, Valencia, Calif., USA) and real-time PCR machine (Stratagene, MX 3005P, USA). Reaction mix and thermal profile were performed conferring to the manufacturer's instructions, with a total volume of 25ul. Primers and probes (Table 1) targeting the 3D gene described by Callahan et al. (2002) Cycle threshold (CT) for each sample was then determined. Positive samples had a CT value of 23.

\section{Conventional Polymerase Chain Reaction and Sequencing}

The conventional reverse transcriptase-polymerase chain reaction was utilized for detection and serotyping of FMD, using Promega Mastermix (GoTag®G2 Green Master Mix, M7822, Promega, USA). Using FMDV primers, the objecting $3 \mathrm{D}$ region was utilized for testing the extracted RNA described by Callahan et al. (2002). The RT-PCR was performed in a one-step method following the manufacturer instructions. Consequently, serotype-specific primers were used for detection of the positive samples tested by universal RT-PCR (Table 2) targeting VP3-2B region for O, A and conferring to Reid et al. (2000), Kandeil et al (2013) respectively and SAT2 as described by $\mathrm{Xu}$ et al. (1993). 1.5\% agarose gel containing $0.5 \mu \mathrm{g} / \mathrm{ml}$ of ethidium bromide was used to analyze the PCR products. UV illumination was used to display the DNA band and DNA molecular weight marker was used to detect the size. Three PCR products from Sharkia 2018, Sharkia 2019, and Ismailia 2020 were sequenced for the VP1 gene using BigDye Terminator in forward and reverse direction. Using the Bio Edit program (version 7.2.5 software), the obtained sequences and other representative sequences from Gene bank were aligned through multiple sequence alignment with clustal W. Using the Kimura 2-parameter nucleotide substitution model, the distance matrices were constructed by using the resulted sequence alignments as described by (Kimura 1980) as implemented in the program MEGA 4.,10 (Tamura et al. 2007), the neighbor-joining trees were established. 
Int J Vet Sci, 2021, 10(3): 162-171.

Table 1: Primers and probe targeting 3D gene of FMDV used for qRT-PCR

\begin{tabular}{llc}
\hline Type & Sequence & Target gene \\
\hline Forward primer & 5'ACTGGGTTTTACAAACCT-3' & 3D \\
Reverse primer & 5'-GCGAGTCCTGCCACGGA-3' & 3D \\
TaqMan probe & 5'FAMTCCTTTGCACGCCGTGG GAC-TAMRA-3' & 3D \\
\hline
\end{tabular}

Table 2: Primer targeting VP3 -2B gene of FMDv

\begin{tabular}{lllcc}
\hline Gene & Target & Sequences & Length & References \\
\hline VP3 & & TACCAAATTACACACGGGAA & & Kandeil et al. (2013) \\
2B & FMDV-A & GACATGTCCTCCTGCATCTG & $863-866$ bp & \\
VP3 & & ACCAACCTCCTTGATGTGGCT & $1301 \mathrm{bp}$ & Reid et al. (2000) \\
2B & FMDV-O & GACATGTCCTCCTGCATCTG & & \\
VP3 & & TGAACTACCACTTCATGTACACAG & $1279 \mathrm{bp}$ & Xu et al. (1993) \\
2B & FMDV-SAT2 & ACAGCGGCCATGCACGACAG & \\
\hline
\end{tabular}

\section{RESULTS}

Rapid Detection of FMDV in Vesicular Fluids and Tongue Epithelium by qRT-PCR using Universal Primer

qReal-time PCR was used for the rapid detection of FMDV in vesicular fluids and tongue epithelium using a universal probe of FMDV targeting the 3D gene. A total of 209 samples collected from different districts in three Egyptian provinces were examined. Positive samples showed cycle threshold (CT) 18-25 (Fig. 1). Samples with $\mathrm{CT}$ values $\leq 25$ which indicate high viral genomic load was considered FMD positive. As shown in table 4, forty-five of the total samples were FMDV positive with $21.5 \%$. FMDV is more prevalent in cattle than buffaloes with a percentage of $31.5 \%$ and $13.6 \%$, respectively. The highest prevalence was recorded in Belbes, sharkia province while the lowest rate was recorded in El-Tal Kabeer Ismailia Governorate (Table 3).

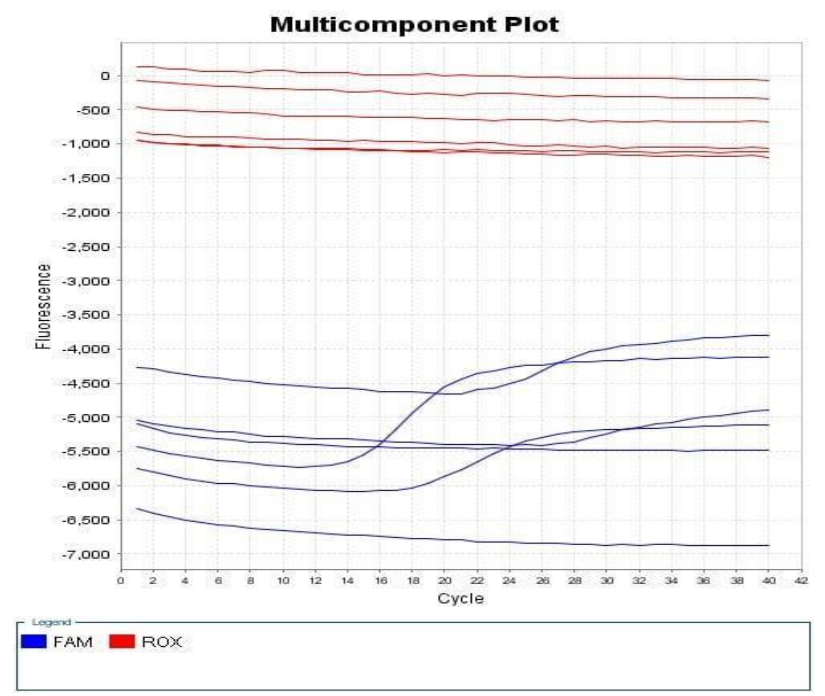

Fig. 1: Ct of 18-25 of Real-time PCR for FMDV +ve samples.

\section{Isolation and Identification of FMDV in BHK21 Cell Culture}

About 45 pooled tongue epithelium and vesicular fluid samples proved positive for FMDV by qRT-PCR using universal primers were submitted for virus isolation in BHK21 cells to determine the sensitivity of each. Samples collected from cattle and buffaloes in the three examined provinces during 2018. Eleven samples out of a total of 209 samples showed specific CPE during 2018. Eleven samples out of 209 samples showed specific CPE on BHK-21 (Table2) characterized by a granulation, cell rounding, and rapid destruction of BHK-21 monolayer cell within $48 \mathrm{~h}$ (Fig. 2, 3 and 4) about 5.26\% when compared with RTPCR (Table 4).

Serotyping of FMDV Distributed in 3 Provinces of Egypt by Conventional RT-PCR using Type-Specific Primers 2019-2020

FMD virus serotypes were determined by RT-PCR using serotype-specific primers. About 38 (18.2\%) of 209 detected samples were positive (Fig. 5). 38 samples out of 209 were serotype SAT2 positive. The most prevalent serotype is SAT2 in all examined provinces respectively when examined by conventional RT-PCR. Neither Serotype A nor serotype $\mathrm{O}$ were detected in any of the examined samples.

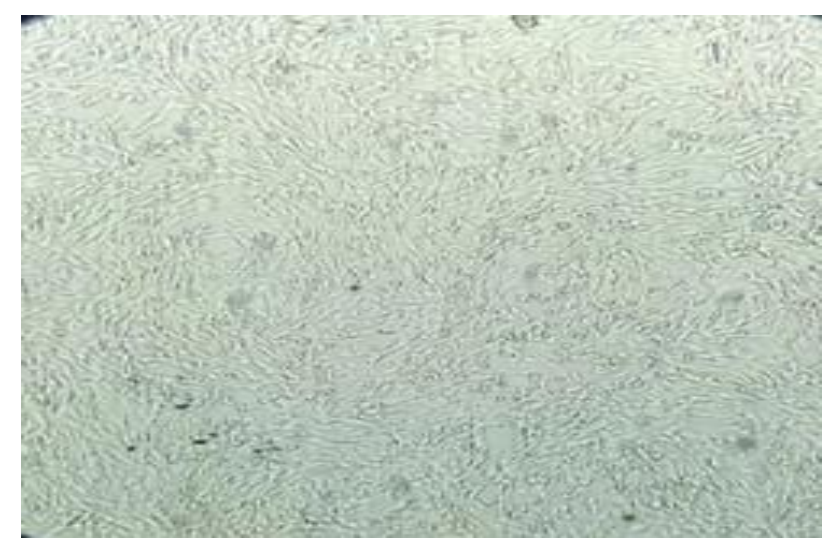

Fig. 2: Normal BHK21 cell, 200x inverted microscope.

\section{Sequencing and Phylogenetic Analysis of VP1 Gene of FMDV-SAT2}

Two FMDV SAT2 samples that give strong positive bands with conventional PCR were selected for sequencing and phylogenetic analysis of the VP1 gene. Two samples from Sharkia province were represented as FMD SAT2 Sharkia-2019 and the second one from Tal Kabeer, Ismailia represented as FMD SAT2 Ismailia-2020. RT-PCR was used to amplify the VP1 coding region of the three samples using specific primers and the products were purified and sequenced in the forward and reverse direction targeting VP3 -2B. But the third sample is FMD SAT2 Sharkia 2018 with accession no (MT745990) is sequenced by using primer sequences targeting the VP1 coding gene (partial VP1 sequencing) as described by Pirbright primer (Table 
5). By BLAST analysis, the Egyptian SAT2 FMDV viruses from 2018 are closely related to (FMD SAT-2 SHARKIA /3/2018) with homology $99.6 \%$ (Fig. 6) and (Fig. 5) indicating FMDV SAT2 strains implicated in FMDV outbreaks during 2018.

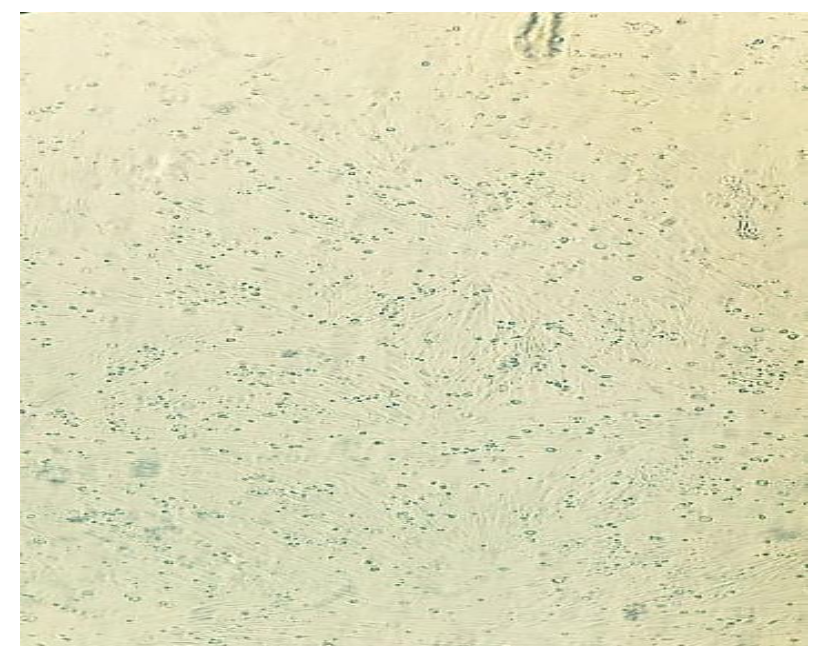

Fig. 3: CPE of FMDV in BHK21 cell culture, 24hr postinoculation, 200X.

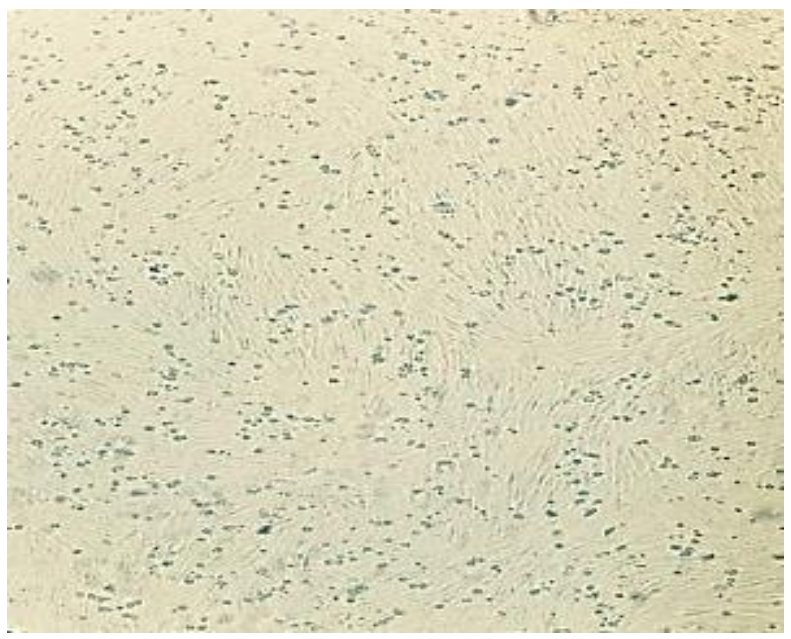

Fig. 4: BHK21 cell culture inoculated with FMDV showed granulation, rounding, and destruction of cells $48 \mathrm{hr}$ postinoculation.

\section{At the Base of Nucleotide and an Amino Acid Sequence of FMD SAT2 Sharika (2018)}

Type SAT2 Identified during 2018: The most closely related strains with type SAT2 identified during,2018 are FMD SAT2 Alex/2/ 2018 and FMD SAT2 Ismalia/3/ 2018 with homology 99.2 and $95.8 \%$ (Fig. 6) and (Fig. 7), respectively. Comparison of SAT2 Sharkia 2018 with other Egyptian isolates published in the gene bank, showed homology percentage ranged from 84.4 to $86.8 \%$ with amino acid substitutions at level 28, 29, 31, 46, 47, and 52 in which alanine replace proline at 28 , alanine replaces proline at 29, alanine replaces serine at 31, threonine replaces serine at 46 , asparagine replaces threonine at 47 and tyrosine replace phenylalanine at 52 respectively. FMD Sharkia SAT2 strain is also closely related to FMD SAT2 /LIB/7/2003 and ALEX 2012 with 85.2\% identity that clustered under (ALEX -12 lineage).
Amino acid sequence comparison of the VP1 coding region of FMDV SAT2 Sharkia 2018 strains at G-H loop showed no difference in RGD tripeptide at the site (33-36) equal to (144-146) (after trimming and modification of the sequences where the primer used in the study cover the only 288bp only) involved in virus attachment to cell receptors, virulence, and protective immunity (Fig 8).

Phylogenetic Tree of FMD SAT2 Sharkia 2018: Tree examination revealed that the present isolate is closely related to FMDV SAT2 Libya/41/2012 of topotype VII under Libya lineage-12 with $93.7 \%$ identity (Fig. 5), with 3 amino acid substitutions at the site 24,28, and 52 in which aspartic acid substituted with valine, threonine substituted with proline and serine substituted with proline respectively (Fig. 6) and (Fig. 7).

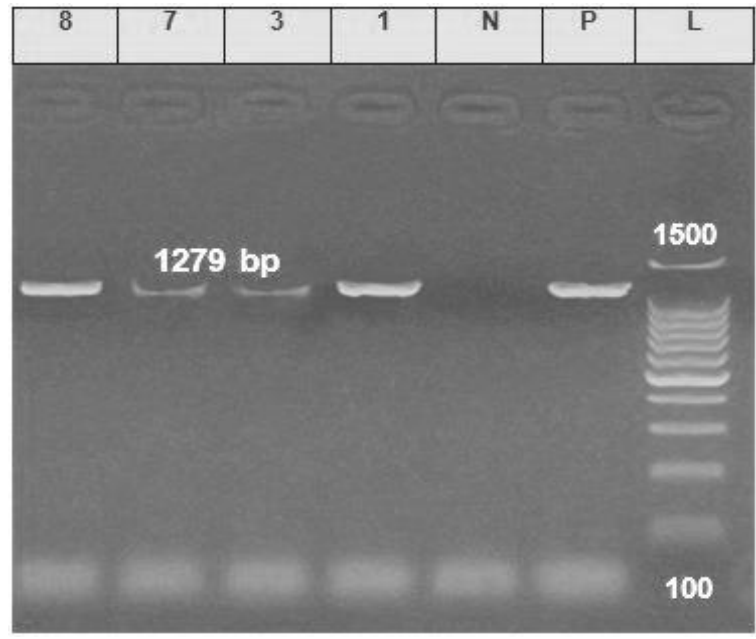

Fig. 5: Agarose gel electrophoresis of conventional RT -PCR products of FMD SAT2 (1279bp), all lanes 1-8 PCR product of VP1 (1, 8 strong positive bands while 3,7 give faint bands) compared with $1500 \mathrm{bp}$ marker.

\section{FMD-SAT2 Sharkia 2019-Ismailia 2020}

By BLAST analysis of FMD SAT2 Sharkia 2019 with accession no (MT745989), FMD SAT2 Ismailia 2020 with accession no (MT745988) revealed that FMD SAT2Ismailia 2020 strain, FMDSAT2 Sharkia 2019 is closely related to Menofia 2018 strain and Libya 2012 Topo type VII with 95.8 and $96.6 \%$ identity indicating that Ismailia 2020 may originate from Libya 2012. Only 3 amino acid substituted at the site 46 and 97,102 in which $\mathrm{K}, \mathrm{T}$, and $\mathrm{P}$ substituted with R, K, and A respectively (Fig. 9, 10 and 11) with Libya 2012 strains (MH814732 lib-12).

Comparison of SAT2 Ismailia VP1 sequence with the closely related Libya 2012 strain (LIB/39/2012-Lib-12) at the level of amino showed a difference in about 6 amino acids which valine (V) replace with (D) aspartic acid at position 95, serine (S)is replaced with Asparagine $(\mathrm{N})$ at position 117, (P) replaced with( $\mathrm{S})$ at position 123, at $99(\mathrm{p})$ proline replaced with $\mathrm{T}$ (Threonine), (E)glutamic is replaced with $(\mathrm{K})$ lysine at 18 and 43 (E) glutamic is replaced with (D) aspartic (Fig 8). On both sides of the RGD sequence region of Sharkia 2018, 2019, and Ismailia 2020 were revealed several differences with the Egyptian SAT2 FMDV 2012 (Fig. 8), no substitutions were observed in the viral RGD Tripeptide involved $d$ in connection of FMDV to the cells (Fig. 9). 
Int J Vet Sci, 2021, 10(3): 162-171.

Percent Identity

\begin{tabular}{|c|c|c|c|c|c|c|c|c|c|c|c|c|c|c|c|c|c|c|c|c|c|c|}
\hline & 1 & 2 & 3 & 4 & 5 & 6 & 7 & 8 & 9 & 10 & 11 & 12 & 13 & 14 & 15 & 16 & 17 & 18 & 19 & 20 & 21 & \\
\hline 1 & & 97.5 & 97.5 & 98.3 & 98.3 & 98.3 & 98.3 & 96.6 & 96.6 & 85.2 & 85.2 & 84.7 & 85.6 & 83.9 & 84.3 & 83.5 & 82.6 & 82.6 & 94.1 & 100.0 & 100.0 & 1 \\
\hline 2 & 2.6 & & 100.0 & 99.2 & 99.2 & 99.2 & 99.2 & 98.3 & 98.3 & 84.7 & 84.7 & 84.3 & 83.9 & 82.6 & 83.9 & 82.2 & 82.2 & 81.4 & 92.4 & 97.5 & 97.5 & 2 \\
\hline 3 & 2.6 & 0.0 & & 99.2 & 99.2 & 99.2 & 99.2 & 98.3 & 98.3 & 84.7 & 84.7 & 84.3 & 83.9 & 82.6 & 83.9 & 82.2 & 82.2 & 81.4 & 92.4 & 97.5 & 97.5 & 3 \\
\hline 4 & 1.7 & 0.9 & 0.9 & & 100.0 & 100.0 & 100.0 & 98.3 & 98.3 & 84.7 & 84.7 & 84.3 & 84.3 & 82.6 & 83.1 & 82.2 & 82.2 & 82.2 & 92.8 & 98.3 & 98.3 & 4 \\
\hline 5 & 1.7 & 0.9 & 0.9 & 0.0 & & 100.0 & 100.0 & 98.3 & 98.3 & 84.7 & 84.7 & 84.3 & 84.3 & 82.6 & 83.1 & 82.2 & 82.2 & 82.2 & 92.8 & 98.3 & 98.3 & 5 \\
\hline 6 & 1.7 & 0.9 & 0.9 & 0.0 & 0.0 & & 100.0 & 98.3 & 98.3 & 84.7 & 84.7 & 84.3 & 84.3 & 82.6 & 83.1 & 82.2 & 82.2 & 82.2 & 92.8 & 98.3 & 98.3 & 6 \\
\hline 7 & 1.7 & 0.9 & 0.9 & 0.0 & 0.0 & 0.0 & & 98.3 & 98.3 & 84.7 & 84.7 & 84.3 & 84.3 & 82.6 & 83.1 & 82.2 & 82.2 & 82.2 & 92.8 & 98.3 & 98.3 & 7 \\
\hline 8 & 3.5 & 1.7 & 1.7 & 1.7 & 1.7 & 1.7 & 1.7 & & 100.0 & 85.2 & 85.2 & 84.7 & 83.5 & 82.6 & 83.9 & 82.2 & 83.1 & 83.1 & 91.1 & 96.6 & 96.6 & 8 \\
\hline 9 & 3.5 & 1.7 & 1.7 & 1.7 & 1.7 & 1.7 & 1.7 & 0.0 & & 85.2 & 85.2 & 84.7 & 83.5 & 82.6 & 83.9 & 82.2 & 83.1 & 83.1 & 91.1 & 96.6 & 96.6 & 9 \\
\hline 10 & 16.7 & 17.3 & 17.3 & 17.3 & 17.3 & 17.3 & 17.3 & 16.7 & 16.7 & & 99.6 & 99.2 & 89.8 & 86.9 & 89.0 & 87.3 & 86.9 & 86.0 & 86.0 & 85.2 & 85.2 & 10 \\
\hline 11 & 16.7 & 17.3 & 17.3 & 17.3 & 17.3 & 17.3 & 17.3 & 16.7 & 16.7 & 0.4 & & 99.6 & 90.3 & 87.3 & 89.4 & 87.7 & 87.3 & 86.4 & 86.0 & 85.2 & 85.2 & 11 \\
\hline 12 & 17.3 & 17.9 & 17.9 & 17.9 & 17.9 & 17.9 & 17.9 & 17.3 & 17.3 & 0.9 & 0.4 & & 90.7 & 87.7 & 89.8 & 88.1 & 87.7 & 86.9 & 86.4 & 84.7 & 84.7 & 12 \\
\hline 13 & 16.4 & 18.6 & 18.6 & 18.0 & 18.0 & 18.0 & 18.0 & 19.1 & 19.1 & 11.1 & 10.6 & 10.1 & & 91.1 & 89.8 & 89.0 & 88.6 & 86.9 & 91.1 & 85.6 & 85.6 & 13 \\
\hline 14 & 18.7 & 20.3 & 20.3 & 20.3 & 20.3 & 20.3 & 20.3 & 20.3 & 20.3 & 14.7 & 14.2 & 13.7 & 9.6 & & 92.4 & 92.4 & 91.9 & 90.7 & 86.9 & 83.9 & 83.9 & 14 \\
\hline 15 & 18.0 & 18.5 & 18.5 & 19.7 & 19.7 & 19.7 & 19.7 & 18.5 & 18.5 & 12.1 & 11.6 & 11.1 & 11.1 & 8.2 & & 93.2 & 92.8 & 91.9 & 87.3 & 84.3 & 84.3 & 15 \\
\hline 16 & 19.1 & 20.8 & 20.8 & 20.8 & 20.8 & 20.8 & 20.8 & 20.8 & 20.8 & 14.3 & 13.9 & 13.3 & 12.1 & 8.1 & 7.2 & & 94.5 & 93.2 & 86.4 & 83.5 & 83.5 & 16 \\
\hline 17 & 20.3 & 20.8 & 20.8 & 20.8 & 20.8 & 20.8 & 20.8 & 19.6 & 19.6 & 14.9 & 14.4 & 13.9 & 12.7 & 8.6 & 7.7 & 5.8 & & 97.9 & 85.2 & 82.6 & 82.6 & 17 \\
\hline 18 & 20.3 & 22.0 & 22.0 & 20.8 & 20.8 & 20.8 & 20.8 & 19.6 & 19.6 & 16.0 & 15.5 & 15.0 & 14.8 & 10.1 & 8.7 & 7.3 & 2.2 & & 84.3 & 82.6 & 82.6 & 18 \\
\hline 19 & 6.2 & 8.1 & 8.1 & 7.6 & 7.6 & 7.6 & 7.6 & 9.5 & 9.5 & 15.8 & 15.9 & 15.3 & 9.7 & 14.8 & 14.2 & 15.3 & 17.0 & 18.2 & & 94.1 & 94.1 & 19 \\
\hline 20 & 0.0 & 2.6 & 2.6 & 1.7 & 1.7 & 1.7 & 1.7 & 3.5 & 3.5 & 16.7 & 16.7 & 17.3 & 16.4 & 18.7 & 18.0 & 19.1 & 20.3 & 20.3 & 6.2 & & 100.0 & 20 \\
\hline \multirow[t]{2}{*}{21} & 0.0 & 2.6 & 2.6 & 1.7 & 1.7 & 1.7 & 1.7 & 3.5 & 3.5 & 16.7 & 16.7 & 17.3 & 16.4 & 18.7 & 18.0 & 19.1 & 20.3 & 20.3 & 6.2 & 0.0 & & 21 \\
\hline & 1 & 2 & 3 & 4 & 5 & 6 & 7 & 8 & 9 & 10 & 11 & 12 & 13 & 14 & 15 & 16 & 17 & 18 & 19 & 20 & 21 & \\
\hline
\end{tabular}

MK493340.1FMD

MK493346.1

MK493347.1

MK493345.1

MK493341.1

MK493342.1

MK493343.1

MK493337.1

MK493338.1

JX570618.1

JX013979.1

KF055861SAT

JX570632.1

AY297948.1FMD

JX570617.1

MF322695.1FMD-

KY825720.1

MF322694. 1

FMD

MK493339.1

MT745990

Fig. 6: Nucleotide similarity of partial sequencing of VP1 gene between FMDV SAT2 Sharkia 2018 and other related strains in the gene bank.

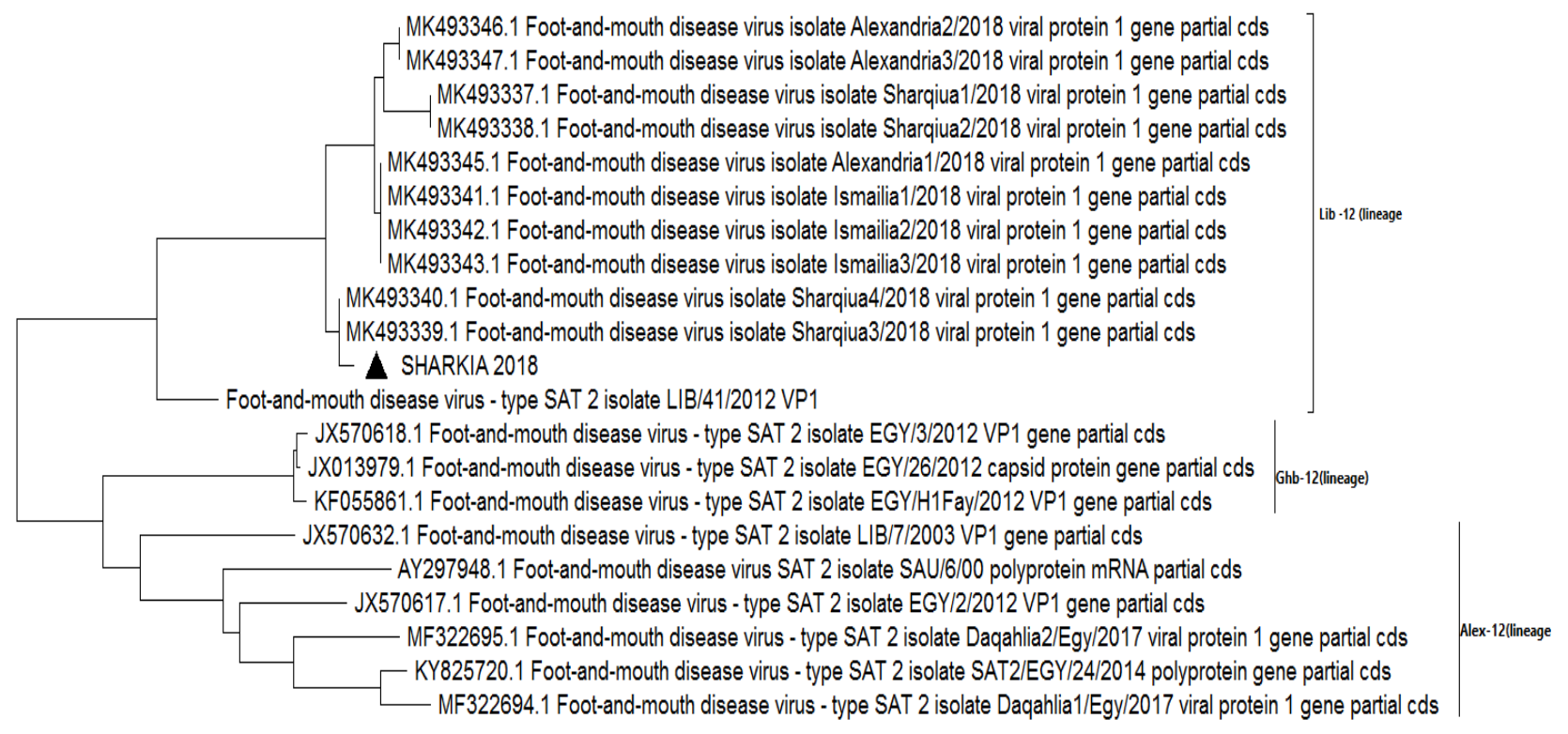

0.020

Fig. 7: Phylogenetic tree of FMDV SAT2 Sharkia 2018 clustered with Libya 2012 lineage genotype VII.

Table 3: Rapid detection of FMDV in cattle and buffaloes using qRT-PCR.

\begin{tabular}{|c|c|c|c|c|c|c|c|c|c|}
\hline \multirow[t]{2}{*}{ Provinces } & \multirow{2}{*}{$\begin{array}{c}\text { Total } \\
\text { Number }\end{array}$} & \multicolumn{2}{|c|}{ Cattle } & \multicolumn{2}{|c|}{ Buffalo } & \multicolumn{4}{|c|}{ Total } \\
\hline & & $+\mathrm{VE}$ & $\%$ & Total & $+\mathrm{VE}$ & $\%$ & Number & $+\mathrm{VE}$ & $\%$ \\
\hline \multicolumn{10}{|l|}{ A. Sharkia } \\
\hline$\overline{\text { Abou Hammad }}$ & 24 & 7 & 29.1 & 20 & 4 & 20.0 & 44 & 11 & 25.0 \\
\hline Diarb Nygm & 15 & 6 & 40 & 21 & 2 & 10 & 36 & 8 & 22.20 \\
\hline Zagazig & 18 & 5 & 27.70 & 27 & 3 & 11.10 & 45 & 8 & 17.70 \\
\hline Belbeis & 3 & 3 & 100 & 3 & 3 & 100 & 6 & 6 & 100 \\
\hline B. Ismailia & & & & & & & & & \\
\hline $\begin{array}{l}\text { El -Tal keber } \\
\text { C. Dakahlia }\end{array}$ & 19 & 6 & 30 & 30 & 1 & 3.30 & 49 & 7 & 14.20 \\
\hline$\overline{\text { Mitghamr }}$ & 13 & 2 & 15.30 & 16 & 3 & 18.70 & 29 & 5 & 17.20 \\
\hline Total & 92 & 29 & 31.50 & 117 & 16 & 13.60 & 209 & 45 & 21.50 \\
\hline
\end{tabular}



10
20
30
40
50
60
70

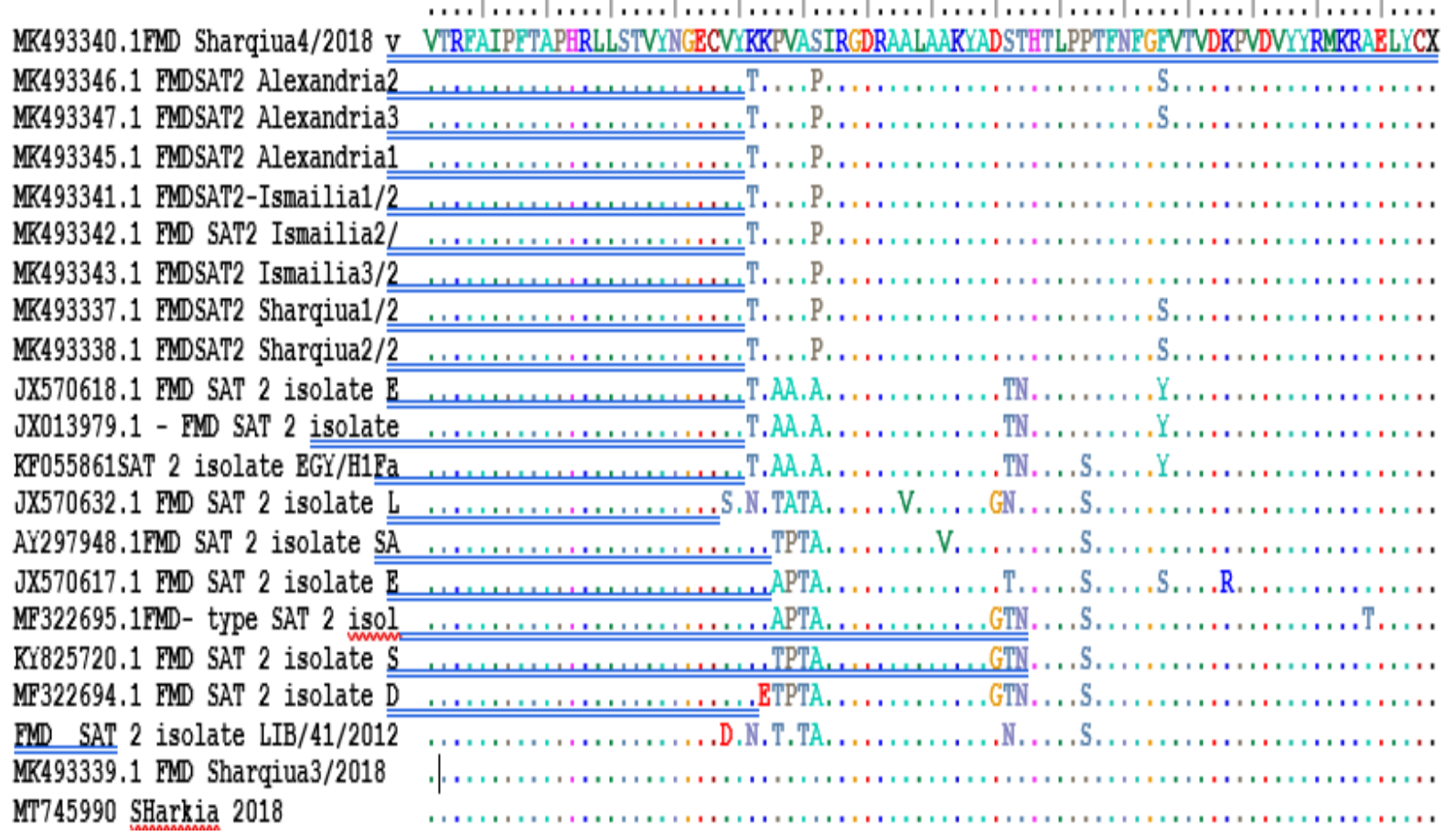

Fig. 8: Amino acid sequence alignment of the Egyptian isolates of FMD SAT-2 (2018).

\begin{tabular}{|c|c|}
\hline AF367101 $\mathrm{NOS} / 4 / 83-1$ & 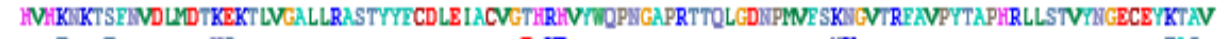 \\
\hline AY442903 SAR/1/01-I & .T.T.T. \\
\hline AF367122 BOT/1/98-II & ......R......K.TQQS \\
\hline Kr112974 8IM/5/87-11 & 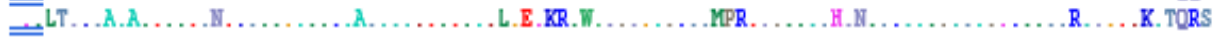 \\
\hline AF367120 8AM/7/96-111 & …....................... \\
\hline AF367124 BOT $/ 29 / 98-111$ & ................ \\
\hline AY343971 TAN/1/86-IV & ......V..............................R.T. \\
\hline $\begin{array}{l}\mathrm{KF} 112961 \mathrm{WYE} / 29 / 90-\mathrm{IV} \\
\mathrm{AP} 479415 \mathrm{GHA} / 2 / 90-\mathrm{V}\end{array}$ & …T. \\
\hline $\begin{array}{l}\text { KF112970 TOG/1/90-V } \\
\text { AF479412 SEN/7/79-VI }\end{array}$ & 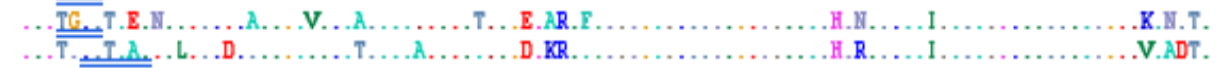 \\
\hline MT199283 SAT2/E1-MenRfia/EGY/2 & 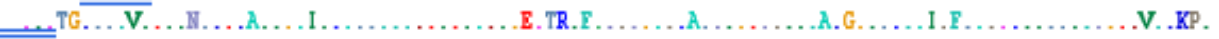 \\
\hline $\begin{array}{l}\text { MK493339 Sharqiua3/2018-Lib-12 } \\
\text { MK493345 Alexandrial/2018-Lib- }\end{array}$ & $\begin{array}{c}\text { TG. } \\
\end{array}$ \\
\hline $\begin{array}{l}\text { MH814723 Lib-12 } \\
\text { MK493341 Ismailial/2018-Lib-12 }\end{array}$ & 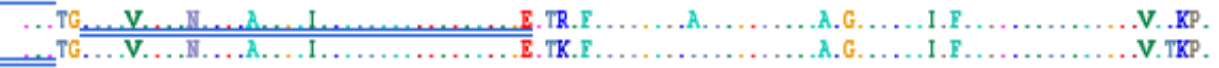 \\
\hline $\begin{array}{l}\text { JX570633 LIB/39/2012-Lib-12 } \\
\text { JX570619 EGY/4/2012-Ghb-12 }\end{array}$ & 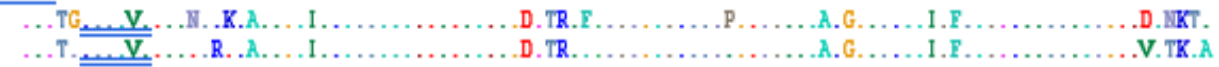 \\
\hline JX013979 EGY/26/2012-Ghb-12 & 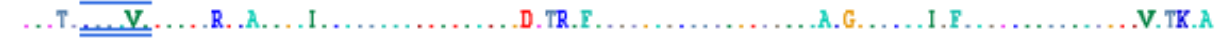 \\
\hline KF055861 EGY/H1Fay/2012-Ghb-12 & 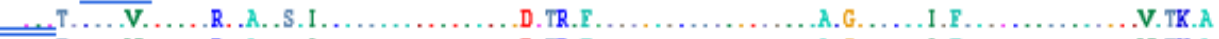 \\
\hline JK570625 EGY/13/2012-Ghb-12 & 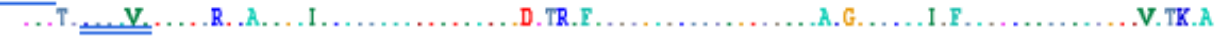 \\
\hline JX570624 EGY/11/2012-Ghb-12 & 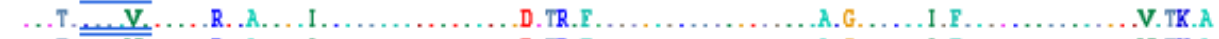 \\
\hline $\mathrm{KT} 055860 \mathrm{EGY} / \mathrm{HlGhb} / 2012$ & $\ldots$ T. \\
\hline JK570617 EGY/2/2012-Alex-12 & 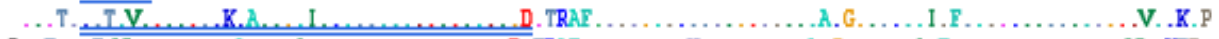 \\
\hline KY825720 SAT2/EGY/24/2014-Alex & 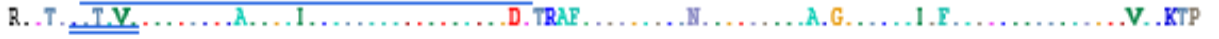 \\
\hline KX258067 EGY/24/2014-Alex-12 & 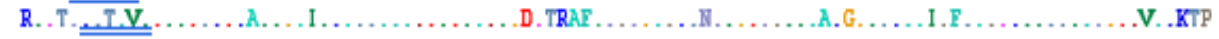 \\
\hline $\begin{array}{l}\text { KK258066 EGY/22/2014-Alex-12 } \\
\text { MF322694 Daqahlial/gqu/2017-A1 }\end{array}$ & $\begin{array}{r}\text { R. T. } \\
\text { T.V.V. } \\
\end{array}$ \\
\hline $\begin{array}{l}\text { KF112930 BUN/4/86-VIII } \\
\text { KT112964 RWA/1/2004-VI1I }\end{array}$ & 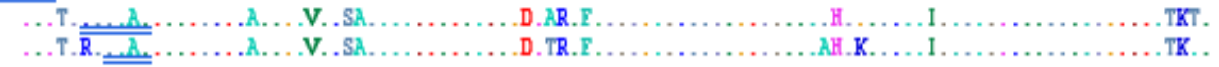 \\
\hline $\begin{array}{l}\text { AY343966 UGA/3/91-IX } \\
\text { HM623680 K65/82-1X }\end{array}$ & 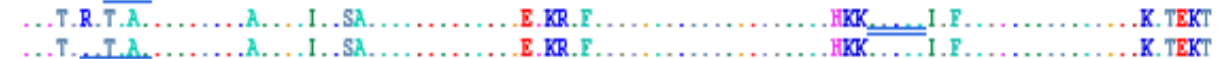 \\
\hline AY343969 UGA/19/98-X & 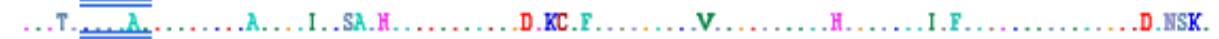 \\
\hline $\begin{array}{l}\text { KF219683 UGA-BUFF } / 12 / 70-\mathrm{X} \\
\text { AF479417-ANG/4/74-XI }\end{array}$ & ‥ TS \\
\hline DQ009736 ANG/04/74-XI & 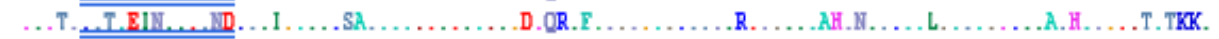 \\
\hline AY343964 UGA/3/76-XII & 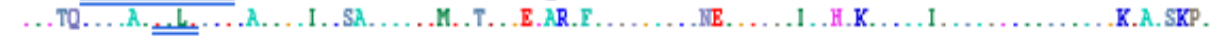 \\
\hline GU566073 SUD/2/2008-XI1I & 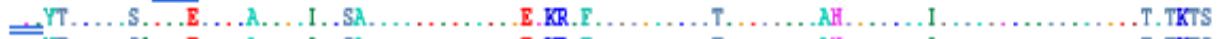 \\
\hline KF112952 ETH/74/2009-XI11 & 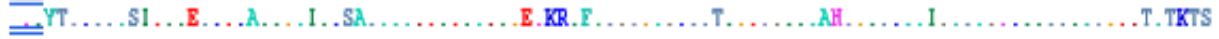 \\
\hline FJ798160 ETH/3/91-XIV & 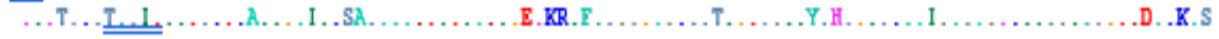 \\
\hline $\begin{array}{l}\text { MT745988 FMD Ismailia-2020 } \\
\text { MT745989 FMD Sharkia-2019 }\end{array}$ & 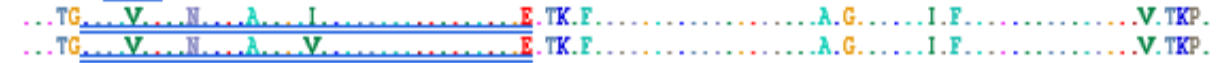 \\
\hline
\end{tabular}

Fig. 9: Amino acid sequence Alignment of VP1-of the FMD SAT2 SHARKIA 2019-2020. 
Int J Vet Sci, 2021, 10(3): 162-171.

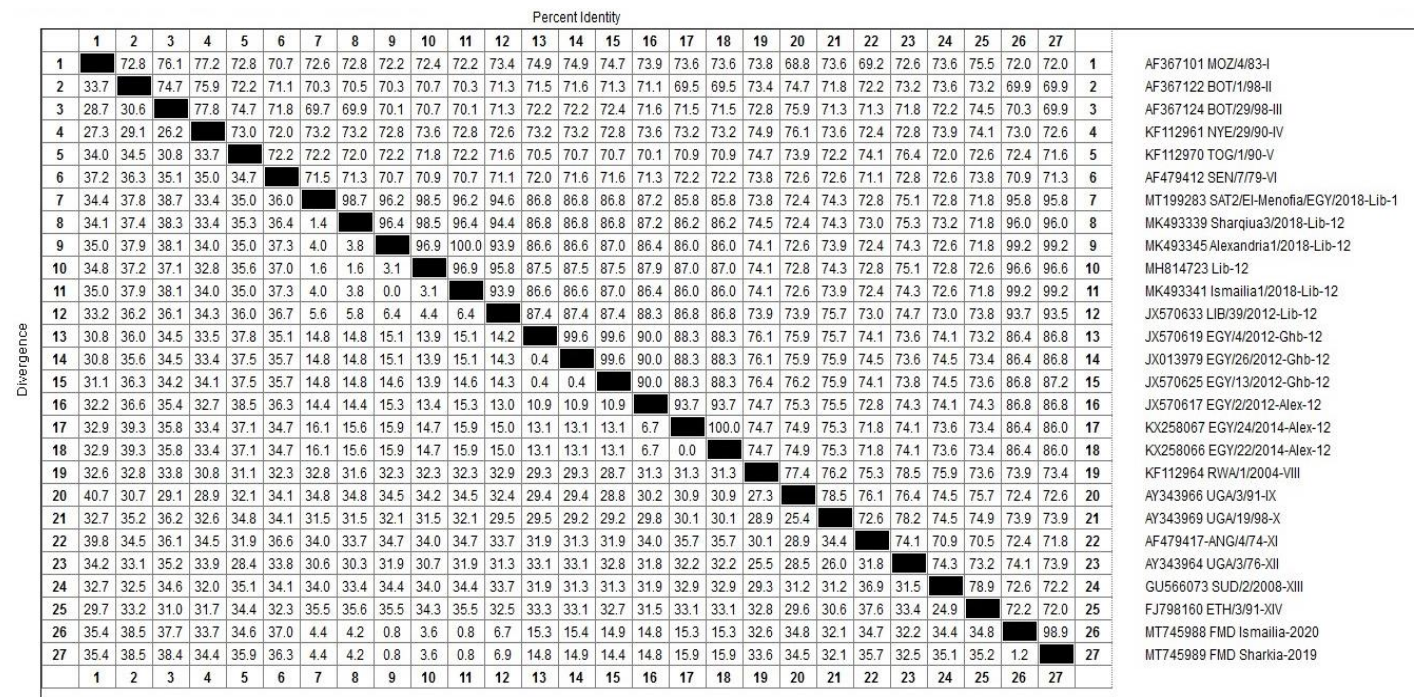

Fig. 10: Nucleotide similarity and divergence \% of FMD SAT2 2019/2020 with other strains in the gene bank.

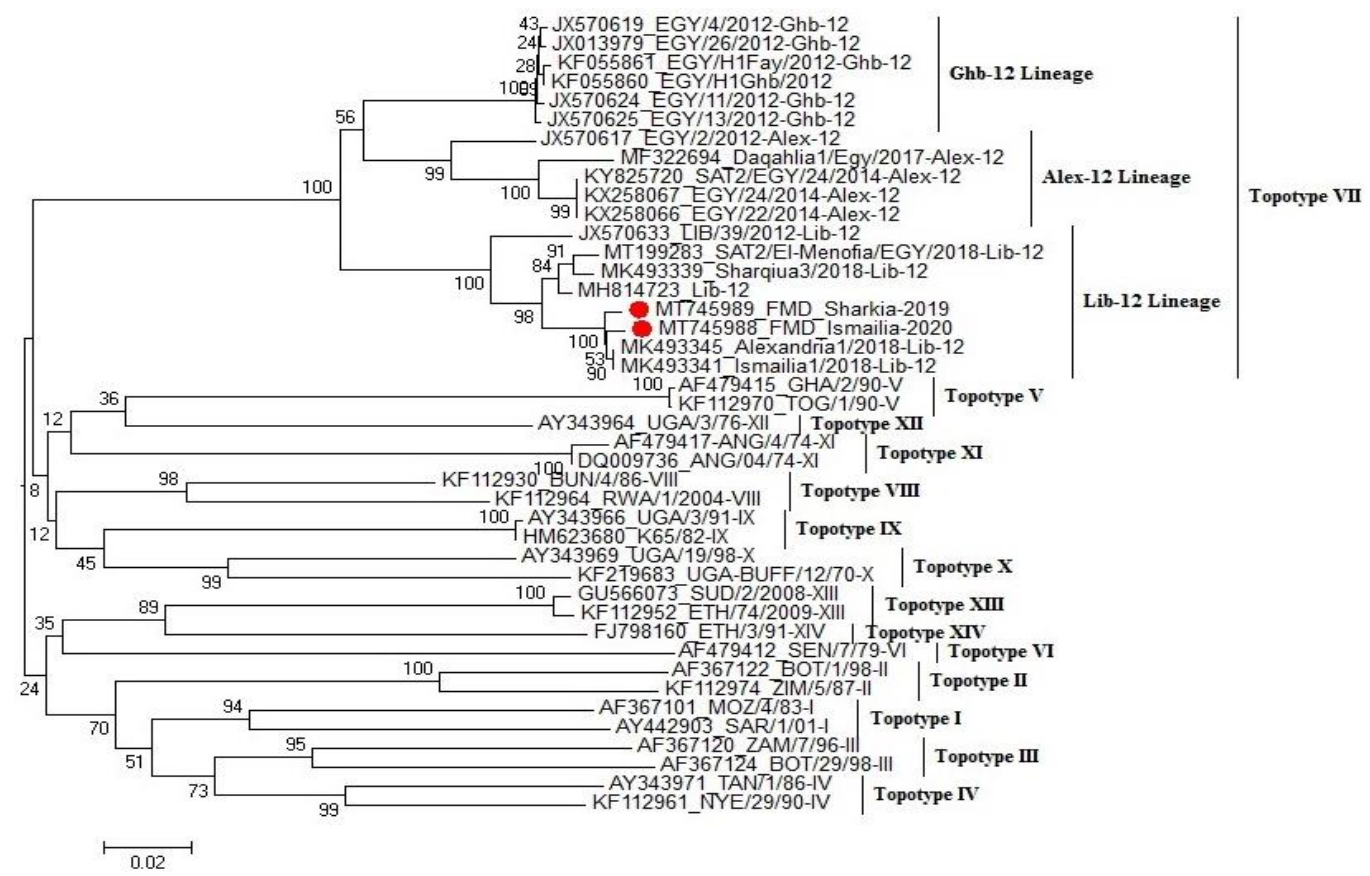

Fig. 11: Phylogenetic tree of FMDV SAT2 Sharkia2019, Ismailia 2020 strain clustered with lineage 2012 genotype VII.

Table 4: Comparative results for virus isolation and qRT-PCR for diagnosis of FMDV in clinical samples

\begin{tabular}{lccccc}
\hline Provinces/ & Total & \multicolumn{2}{c}{ qRT-PCR } & \multicolumn{2}{c}{ Virus isolation } \\
\cline { 3 - 6 } Districts & & Positive & $\%$ & Positive & $\%$ \\
\hline A.Shakia & & & & & \\
$\quad$ Cattle & 60 & 21 & 35 & 2 & 3.30 \\
$\quad$ Buffalos & 71 & 12 & 29.50 & 2 & 2.80 \\
B.Ismailia & & & & & \\
$\quad$ Cattle & 19 & 6 & 31.60 & 3 & 15.70 \\
$\quad$ Buffaloes & 30 & 1 & 3.30 & 2 & 6.66 \\
C.Dakahlia & & & & & \\
$\quad$ Cattle & 13 & 2 & 15.40 & 1 & 7.60 \\
$\quad$ Buffaloe & 16 & 3 & 18.70 & 1 & 6.25 \\
Total & 209 & 45 & 21.50 & 11 & 5.26 \\
\hline
\end{tabular}

Table 5: Sequences of primers used for FMDV-SAT2 sequencing (Pirbright)

\begin{tabular}{llc}
\hline Primers & Sequence & $\begin{array}{c}\text { Size of DNA } \\
\text { product bp }\end{array}$ \\
\hline $\begin{array}{l}\text { Forward primer } \\
\text { Reverse primer }\end{array}$ & GTAACCCGCTTTGCCATC & \\
\hline
\end{tabular}

Comparing our isolates (FMD SAT2 Ismailia 2020 FMD SAT2Sharkia 2019) revealed that, they are related to Alex 2012 isolates of (KX258067 EGY/24/2014-Alex-12 with homology 86.8 , and $86.6 \%$, respectively and $86.8 \%$ with Gharbia isolates (JX013979EGY/26/2012-GH-12 Lineage. While Ethiopian isolates (FJ798160 ETH/3/91 of Topotype XIV) share about $72 \%$ (Fig. 9). The phylogenetic analysis of the three samples showed that the characterized strains are clustered in Topotype VII, Lib12 lineage (Fig. 7; 11).

\section{DISCUSSION}

FMD is one of the most important agents affecting cloven-hoofed animals in the world and causes extensive economic losses (James and Rushton 2002). Direct, indirect losses are the result of the economic impact of FMDV (Knight-Jones and Rushton 2013). Annually, FMD affected the economic status of the endemic countries of 
the world, resulting in extensive losses of livestock industry between USD 6.5 and 21 billion, while losses caused by outbreaks in FMD free countries and zones are more than USD 1.5 billion per year (Knight-Jones and Rushton 2013).

Egypt is a developing country that depends on the importation of meat and live animals for decreasing the gap bet consumption and production. That gives the chance for the introduction of new FMDV strains through the movement of infected animals across international borders. Both Asian and African FMDV strains were introduced into Egypt, which facilitated by its unique location between continents (Sobhy et al. 2018).

In Egypt, since 1951 has a long history with FMDV infection with several incursions (Diab et al. 2019). In these outbreaks, many topotypes and lineages were inculpated. The evolution of new serotypes or topotypes is usually accompanied by the importation of animals from enzootic African countries, the use of inconvenient vaccines, making the animals exposed to infections with antigenically nontypical strains of FMDV and breakthrough herd immunity (Nampana et al. 2013).

FMDV serotypes are molecularly characterized especially, throughout outbreaks to use the most suitable emergency vaccine and trace the source of infection (Paixão et al. 2008; El-Shehawy et al. 2012). The emergence of newly invasive serotype or previously enzootic ones observed frequently from time to time in Egypt, Although the application of annually obligated vaccine in Egypt.

The FMDV serotypes were endemic in many governorates of Egypt encompassing serotype O, A, SAT2, (Ahmed et al.2012).latterly, by continuous monitoring and molecular characterizations reported circulation of many topotypes including topotype( EA-3), genotype IV(African topotype), and Alex-12 lineage(topotypes VII) strains of serotypes O, A, and SAT2, respectively (Knowles et al. 2007; Ahmed et al. 2012; Soltan et al. 2017).

Egyptian veterinary authorities started an emergency vaccination campaigns using the regularly used trivalent vaccines of serotype $\mathrm{O}$, topotype ME-SA, Panasia2 lineage; serotype A, Asian topotype, Iran-05 lineage; and serotype SAT2, topotype VII, Gharbia12 lineage) and locally produced univalent vaccine containing exotic strain (Serotype SAT2, topotype VII, Lib12 lineage) as described by Soltan et al. (2019) manufactured by the Middle East for Veterinary Vaccines (MEVAC, Egypt).

By OIE in 2012 reported that the FMD SAT2 serotype was responsible for the outbreak during 2012. Many outbreaks of FMD in the Delta area and a few along the Nile in the southern parts of the country were recorded. FMDv affects cattle and buffalo, were causing severe clinical signs in young buffalo with sudden death because of a lack of maternal immunity (FAO 2012).

In Egypt consisted of two lineages of FMD -SAT2 fixed as SAT 2/VII/Ghb-12, and SAT 2/VII/Alx-12 which located under topotype VII originated from FMDV SAT2 Libya strain 2012, which isolated from Gharbia and Alexandria governorates respectively was detected in Alexandria Governorate as reported by Ahmed et al (2012).

In 2018, there is a dramatic surge of FMDV cases in East Africa due to O/EA-3 with onward spread into North Africa and additional spreading of the O/ME-SA/Ind2001lineage into Malaysia (OIE and FAO 2018). East Asian countries detected (at least four) serotype $\mathrm{O}$ lineages, with new FMD outbreaks in Palestine and Israel in 2018 (OIE and FAO 2018). Probability of spreading of SAT2(topotype VII) FMDv lineage from West Africa to North Africa matching the incursions of A/AFRICA/G-IV in 2017and O/EA-3 in 2018 (OIE 2019).

The possibility of emerging new FMDV strains is due to a high mutation rate. Continuous monitoring, genetic and antigenic characterization of circulating FMDV strains are required to ensure good effective vaccination and effective control (Mahaptra et al. 2017). In our study, during sample collection, the clinical signs demonstrated and indicated in our results, are in close agreement with the findings of Grubman and Baxt (2004).

In the current study, molecular characterization of FMDV is a very important tool in the identification and serotyping of the virus. We targeted 2 genes in the FMDV genome, the first 3Dgene is highly conserved and used as universal for FMDV identification (Jamal and Belsham 2013). The second VP1 gene is serotype-specific used for serotyping and genotyping of FMDV (Jamal et al. 2013). The genetic characterization of FMD variants can be detected by nucleotide sequencing of the VP1 coding region which responsible for attachment, introduction to FMD cells and protective immunity (Grubman and Baxt 2004).

Real-time RT-PCR provided an extremely sensitive and rapid technique that contributed to improving laboratory diagnosis of FMD (Shaw et al. 2004; OIE 2008; Laila et al. 2011). FMDV SAT2 specific primers used in RT-PCR assay for detection of the virus in field samples of epithelium tissue. Previous authors, (Reid et al. 1999 and 2000), used serotype-specific primers designed from 1D and $2 \mathrm{~B}$ regions of FMD viral genome for detection and identification of FMDV serotypes.

In this study, BHK21cell culture was used to isolate FMDV from tongue epithelium and vesicular fluids collected from cattle and buffaloes as in (Fig. 2, 3, and 4) Two sequential passages were applied for the propagation of FMFV in each FMD suspected samples which show granulation and rounding of cells followed by cell destruction later. The obtained results were observed as reported previously (El-Sayed et al. 2013; Huang et al 2011). The results of viral isolation indicated that Eleven samples out of a total of 209 samples showed specific CPE characterized by granulation, cell rounding, and rapid destruction of BHK-21 monolayer cell within 48h-72 has described by Yeneneh et al. (2020) and Ding et al. (2013) These results in agreement with (Attia et al .2016) who reported that virus isolation on BHK-21 is the most reliable diagnostic method. These findings were in close agreement with the findings of Amr Hassan 2016) who described the infectivity and antigenicity of the virus yield were examined at $24 \mathrm{hr}$. The low level of viral isolation may be attributed to $\mathrm{pH}$ levels and climatic changes which lead to decrease infectivity of the isolated virus, as the level of isolation on BHK21 may have depended on a live virus, as reported earlier (Shaw et al. 2004; Yeneneh et al. 2020).

Viral isolation is still the "golden standard" for the diagnosis of FMD disease (Admassu 2015). The definitive proof for the presence of active FMDV is the virus isolation. The existence of a live infectious virus should be desired for effective viral isolation. Up to 4 days to monitor the presence of the virus when the levels of virus are weak predominately (Jamal and Belsham 2013). 
The results of conventional RT-PCR assays in this study (Table 5), indicated that FMDV SAT2 was detected in Egypt during 2018-2020. The most prevalent serotype responsible for the outbreaks is SAT2 and this is in alignment with the findings reported earlier (Ahmed et al. 2012; FAO 2012; Kandeil et al. 2013; ElShehawy et al. 2014; Soltan et al. 2018). Furthermore, the low detection rate of serotypes $\mathrm{A}$ and $\mathrm{O}$ is supported by (Kandeil et al. 2013), who stated that the low incidence of serotypes A and $\mathrm{O}$ may be due to regular vaccination control in Egypt during the period of study.

But in 2015-2016 the genotyping data of Egyptian FMD V (especially in southern Egypt) indicate coinfection with different serotypes of FMDV of O, SAT2, as reported by Al-Hosary et al. (2019).

The genetic characterization of FMD variants can be detected by nucleotide sequencing of the VP1 coding region which responsible for attachment, entry to FMD cells, and protective immunity (Grubman and Baxt 2004).

In the current study, sequence alignment and phylogenetic analysis were illuminated to understand the relationship of the Egyptian strains that were aligned with FMD SAT2 strains restored from Genbank. The results in close agreement with the conclusion of El-Shehawy et al. (2014), who reported that Egyptian SAT2 belonged to topotype VII which appeared again in Egypt after an apparent gap of 64 years. Moreover, topotype VII has been circulating in the region for at least 14 years (Kandeil et al. 2013).

The obtained VP1 nucleotide sequence of serotype SAT2 Sharkia 2018 and 2019 strains were compared as shown in (Fig. 6 to 10) with other isolates in the database indicated that the detected strain is closely related to SAT2/LIB/41/2012, SAT-2, Ismailia/1.2.3/2018 which belong to topotype VII and other Egyptian isolates published during 2018, these results in alignment with the findings of Soltan et al. (2019) who expected that Egyptian outbreaks of FMDV SAT2 during the period of 2018 - 2019 may be originated from Libya. Also, these results in close agreement with the findings of Hagag et al. (2019) who detected that FMD SAT2 circulated in Egypt in 2018-2019 and reported reemergence of FMD serotype O Manisa in Egyptian cattle in 2019.

\section{Conclusion}

From the obtained results we can conclude that i) FMDV is prevalent in Sharkia, Dakahlia, and Ismailia governorates, SAT2 serotype still circulating in the three provinces from 2018 to 2020, indicating effective vaccination against FMDV serotype $\mathrm{O}$ and $\mathrm{A}$, ii) FMDV SAT2 Sharkia 2018, 2019, and Ismailia 2020 VP1 sequence are identical and closely related to other Egyptian strains circulating from 2012 to 2018 as Menophia, Alexandria, and Gharbia, iii) qRT-PCR is a rapid technique that can detect FMDV in clinical samples within $2 \mathrm{hr}$ from the onset of clinical signs, iv) Phylogenetic tree constructed for FMDV SAT2clustered Sharkia 2018, 2019, and Ismailia 2020 strains within SAT2 topotype VII, v) FMDV SAT2 Sharkia 2018, 2019, and Ismailia 2020 VP1 sequence is identical and closely related to Libya 2012 indicating that these viruses may originate from Libya, vi) Despite Egyptian veterinary authorities started emergency vaccination campaigns using the regularly used trivalent vaccines (serotype O, topotype ME-SA, Panasia2 lineage; serotype A, Asian topotype, Iran05 lineage; and serotype SAT2, topotype VII, Gharbia12 lineage) and locally produced monovalent vaccine containing exotic strain (SerotypeSAT2, topotype VII, Lib-12 lineage) manufactured by the Middle East for Veterinary Vaccines (MEVAC, Egypt). FMD SAT2 is still circulated in Egypt Requiring continuous monitoring and characterization of the circulating strains to update the vaccine seeds to ensure effective vaccination.

\section{Author's Contribution}

MSE was involved in designing and planning the protocol of the study and supervised the work. SAS aided in interpreting the results revised the simulations. SMMI performed the studies. All authors were involved in manuscript writing and approved final version.

\section{REFERENCES}

Admassu B, Getnet K, Shite A and Mohammed S, 2015. Review on foot and mouth disease: distribution and economic significance. Academic Journal of Animal Diseases 4: 160169. http://doi.org/10.5829/idosi.ajad.2015.4.3.95165

Ahmed HA, Salem SAH, Habashi AR, Arafa AA, Aggour MGA, Saleg GH, Gaber AS, Salem O, Abdelkader SH, Knowels NJ, Madi M, Valdazo-Gonzalez B, Wadsworth J, Hutchings GH, Miuolet V, Hammond JM and King DP, 2012. The emergence of foot-and-mouth disease virus SAT2 in Egypt during 2012. Transboundary and Emerging Diseases 59: 476-481. https://doi.org/10.1111/tbed.12015

Alexandersen S, Forsyth MA, Reid SM and Belsham GJ, 2000. Development of reverse transcription-PCR (oligonucleotide probing) enzyme-linked immunosorbent assays for diagnosis and preliminary typing of foot-and-mouth disease: A new system using simple and aqueous-phase hybridization. Journal of Clinical Microbiology 38: 4604 4613. https://doi.org/10.1128/JCM.38.12.4604-4613.2000

Al-Hosary AA, Kandeil A, El taweel AN, Nordengrahn A, Merza M, Bardra R, Kayali G and Ali M, 2019. Co-infection with different serotypes of FMDV in vaccinated cattle in Southern Egypt. Virus Genes 55: 304-331. https://doi.org/10.1007/ s11262-019-01645-3

Bachrach HL, 1968. Foot and mouth disease. Annual Review of Microbiology 22: 201-244. https://doi.org/10.1146/annurev. mi.22.100168.001221

Callahan JD, Brown F, Osorio AF, Sur JH, Kramer E, Long GW, Lubroth J, Ellis SJ, Shoulars KS, Gaffney KL, Rock DL and Nelson WM, 2002. Use of a portable real-time reverse transcriptase-polymerase chain reaction assay for rapid detection of foot-and-mouth disease virus Journal of The American Veterinary Medical Association 220: 1636-1642. https://doi.org/10.2460/javma.2002.220.1636

Diab E, Bazid AI, Fawzy M, El-Ashmawy WR, Fayed AA and El-Sayed M, 2019. Foot and mouth disease outbreaks in Egypt during 2013-2014: Molecular characterization of serotypes A, O, and SAT2. Veterinary World 12: 190-197. https://doi.org10.14202/vetworld.2019.190-197

Ding YZ, Chen J, Zhang JH, Zhou LN, and Ma LN, 2013. An overview of control strategy and diagnostic technology for foot-and-mouth disease in China. Virology Journal 10: 78. http://doi.org/10.1186/1743-422X-10-78

El-Sayed EIM, Arab RMH, Abou Zeid AA, Bakr AAM and Khodeir MH, 2013. A limited Sero-Surveillance of Foot and Mouth Disease in sheep in Egypt. Journal of Advanced Veterinary Research 3: 12-15.

El-Shehawy LI, Abu-Elnaga HG, Fawzy M, Abdel Atty, AlWatany H, Moussa FA and Mansour AE, 2012. Foot-and- 
Mouth disease virus SAT2 isolates and vaccine strain in Egypt (2014-2015). Egyptian Journal of Veterinary Sciences 45-46: 25-32.

EL-Shehawy LI, AbuElnaga H, Rizk SA, Abd El-Kreem AS, Mohamed AA and Fawzy HG, 2014. Molecular Differentiation and Phylogenetic analysis of the Egyptian foot-and-mouth disease virus SAT2. Archives of Virology 159: 437-443. https://doi.org/10.1007/s00705-013-1825-1

FAO, 2012. Foot-and-mouth disease caused by serotype SAT2 in Egypt and Libya. EMPRS Watch Vol. 25: pages 1-7. http://www.fao.org/3/an380e/an380e00

Grubman MJ and Baxt B, 2004 Foot-and-mouth disease. Clinical Microbiology Review 17: 465-493. https://doi.org/10.1128/ CMR.17.2.465-493.2004

Hagag NM, Hamdy ME, Sargious MA, Elnomrosy SM, Ahmed NA, Hamed AA, Habashi AR, Ibrahiem EI, Abdel-Hakim MA and Shahein MA, 2019. Molecular and Genetic Characterization of Newly Circulating Foot and Mouth Disease Virus (FMDV) Serotype SAT2 in Egypt during2018 and Early 2019. Host and Viruses 6: 103-108. https://doi.org/10.17582/journal.hv/2019/6.5.103.108

Huang X, Li Y, Fang H and Zheng C, 2011. Establishment of persistent infection with foot and mouth disease virus in BHK-21 cells. Virology Journal 8: 169. https://doi.org/ 10.1186/1186/1743-422X-8-169

ICTV, 2000. Virus Taxonomy. Seventh Report of the International Committee on Taxonomy of Viruses. Academic Press, San Diego, USA pp: 1162.

Jamal S and Belsham GJ, 2013. Foot-and-mouth disease: Past, present, and future. Veterinary Research 44: 116. https// doi.org/10.1186/VetReasearch.2013.116

James AD and Rushton J, 2002. The economics of foot and mouth disease. Revue Scientifique et Technique 21: 637644. http:// doi.org/10.20506/10.20506/rst.21.3.1356

Kandeil A, El-Shesheny R, Kayali G, Moatasim Y, Bagato O, Darwish M, Gaffar A, Younes A, Farag T, Kutkat MA and Ali MA, 2013. Characterization of the recent outbreak of foot-and-mouth disease virus serotype SAT2 in Egypt. Archives of Virology 158: 619-627. https//doi.org/ 10.1007/s00705-012-1529-y

Kasambula L, Belsham GJ, Siegismund HR,Muwanika VB, Ademun-Okurut AR and Masembe C, 2012. Serotype identification and VP1 coding sequence analysis of foot-andmouth disease viruses from outbreaks in Eastern and Northern Uganda in 2008/9. Transboundary and Emerging Diseases 59: 323-330. https://doi.org/10.1111/j.18651682.2011.01276.x

Kimura M, 1980. A simple method for estimating evolutionary rates of base substitutions through comparative studies of nucleotide sequences. Journal of Molecular Evolution 2: 111-120. https://doi.org/10.1007/BF01731581

Knight-Jones TDJ and Rushton J, 2013. The economic impacts of foot and mouth disease-what are they, how big are they and where do they occur? Preventive Veterinary Medicine 112: 161-173. http://doi.org/10.1016/j.prevetmed. 2013.07.013

Knowles NJ, Wadsworth J, Reid SM, Swabey KG, El-Kholy AA, Abd El-Rahman AO, Soliman HM, Ebert K, Ferris NP, Hutchings GH, Statham RJ, King DP and Paton DJ, 2007. Foot-and-mouth disease virus serotype A in Egypt. Emerging Infectious Diseases 13: 1593-1596. https://doi.org/10.3201/10.3201/eid1310.070252

Mahapatra M, Upadhyaya S, Aviso S, Babu A, Hutchings G and Parida S, 2017. Selection of vaccine strains for serotype O foot-and-mouth disease viruses (2007-2012) circulating in Southeast Asia. East Asia Far East. Vaccine 35: 7147-7153. https //doi.org/10.1016/vaccine.2017.7147-7153

Nampana S, Richards J, Khounsy S, Inthavong P, Yang M, Rast $\mathrm{L}$ and Windsor $\mathrm{P}, 2013$. Investigation of foot and mouth disease hotspots in northern Lao PDR. Transboundary Emerging Diseases 60: 315-329. https://doi.org/10.1111/j. $\underline{1865-1682.2012 .01350 . \mathrm{x}}$
Negussie H, Kyule MN, Yami M, Ayelet G and Jenberie S, 2011. Outbreak investigations and genetic characterization of footand-mouth disease virus in Ethiopia in 2008/2009. Tropical Animal Health and Production 43: 235-243. https://doi.org/ 10.1007/s11250-010-9683-2

Nermeen SG, Darwish DM, Abousenna MS, Galal M, Ahmed AR, Attya M, Saad MA and Abdelhakim M, 2019. Efficacy of a commercial local trivalent Foot and Mouth Disease (FMD) vaccine against recently isolated O-EA3. International Journal of Veterinary Science 8: 35-38.

OIE, 2019. World organization of animal health. The official 2019-1. www.oiebulletin.com

Paixão TA, Carvalho AVN, Paiva NO, Reis JR, Barbosa MS, Serra CV, Silva RR, Beckham TR, Martin BM, Clarke NV, Adams LG and Santos RL, 2008. Diagnosis of foot-andmouth disease by real-time reverse transcription-polymerase chain reaction under field conditions in Brazil, 2008. BMC Veterinary Research 4: 53. https://doi.org/10.1186/17466148-4-53

Reid SM, Grierson SS, Ferris NP, Hutchings GH and Alexandersen S, 2003. Evaluation of automated RT-PCR to accelerate the laboratory diagnosis of foot-and-mouth disease virus. Journal of Virological Methods 107: 129139. https://doi.org/ 10.1016/s0166-0934(02)00210-0

Reid SM, Hutchings G H, Ferris NP and De Clercq K, 1999. Diagnosis of foot-and-mouth disease by RT-PCR: evaluation of primers for stereotypic characterization of viral RNA in clinical samples. Journal of Virological Methods 83: 113123. https:// doi.org/ 10.1016/s0166-0934(99)00113-5

Reid SM, Ferris NP, Hutchings GH, Samuel AR and Knowles NJ, 2000. Primary diagnosis of foot and mouth disease by reverse transcription polymerase chain reaction. Journal of Virological Methods 89: 167-176. https://doi.org/10.1016/ s0166-0934(00)00213-5

Shaw AE, Reid SM, King DP and Hutchings GH, 2004. Enhanced laboratory diagnosis of foot and mouth disease by real-time polymerase chain reaction. Revue Scientifique et Technique 23: 1003-1009. http://doi.org/10.20506/ 10.20506/rst.23.3.1544

Sobhy NM, Mor SK, Mohammed MEM, Bastawecy IM, Fakhry HM, Youssef CRB, and Goyal SM, 2014. Phylogenetic analysis of Egyptian foot and mouth disease virus endemic strains. The Journal of American Science 10: 133-138

Soltan MA, Dohreig RMA, Abbas H, Ellawa M, Yousif I, Aly AE, Wasfy M and Elsayed MM, 2019. The emergence of foot and mouth disease virus, Lib-12 lineage of topotype VII, serotype SAT2 in Egypt, 2018. Transboundary Emerging Diseases 66: 1105-1106. https:// doi.org/10.1111/tbed.13152

Soltan MA, Negmaldin AH, El-Diasty MM, Mansour Sh M G and Elbadry M A, 2017. Molecular characterization of circulating Foot and mouth disease virus (FMDV) serotype O topotype EA-3 and serotype A (African topotype) genotype IV in Egypt, 2016. Veterinary Microbiology 208: 89-93. https://doi.org/ 10.1016/j.vetmic.2017.07.018

Tamura K, Dudley J, Nei M and Kumar S, 2007. Molecular Evolutionary Genetics Analysis (MEGA) software version 4.0. Molecular Biology and Evolution 24: 1596-1599. https://doi.org/ 10.1093/molbev/msm092

World Reference Laboratory Pirbright FMD (WRL FMD), 2017. Molecular Epidemiology/Genotyping, OIE/FAO FMD Reference Laboratory Network Reports

Xu A, Van ejik M, Park C and Lewin HA, 1993. Polymorphism in BoLA-DRB3 exon 2 correlates with resistance to persistent lymphocytosis caused by bovine leukemia virus. Journal of Immunology 151: 6977-6985.

Yeneneh T, Fazlurrahman K and Esayas G, 2020. Molecular characterization of foot-and-mouth disease viruses collected from Northern and Central Ethiopia during the 2018 outbreak. Veterinary World 13: 542-548. https://doi.org/ $\underline{10.14202 / \text { vetworld.2020.542-548 }}$ 